\title{
New Al laboratory for the NHS
}

\author{
(ㄷ) (ब) $\Theta$ OPEN ACCESS \\ The public must be engaged in Al innovations to ensure real benefits for health
}

\section{Adam Steventon director of data analytics, Sarah R Deeny assistant director of data analytics, Josh Keith senior fellow, Arne T Wolters senior analytics manager}

Health Foundation, London EC4Y 8AP, UK

In August 2019 the UK government announced a welcome boost for artificial intelligence (AI) in healthcare, with $£ 250 \mathrm{~m}$ (€280m; \$310m) for a national laboratory in England. ${ }^{1}$ Public imagination is captivated by robots, but the new lab will prioritise technologies more likely to benefit the health system and patients in the short term, including algorithms to predict demand for hospital beds and tools that identify signs of disease from diagnostic images, all underpinned by a focus on ethical and fair $\mathrm{AI}{ }^{2}$

\section{Clear priorities}

Many healthcare professionals rely on paper records and outdated technology, and struggle to access basic information at the point of care. Investment is needed, but this must be matched with a credible national strategy for $\mathrm{AI}$ and data analytics that focuses on the needs of patients and the health system rather than technology for technology's sake. The priorities of NHSX, the national agency for digital transformation in healthcare that will host the AI lab, ${ }^{3}$ include reducing clinicians' workloads, giving patients tools to access services directly, ensuring clinical information can be accessed safely where needed, enhancing patient safety, and improving productivity. These welcome priorities must be accompanied by a needs driven approach throughout the technology development process.

A clearer focus on improving health inequalities is also required. The history of AI's effect on marginalised communities is sobering $^{4}$ and shows that we must go beyond widening internet access to ensuring that new technology is developed together with underserved communities and that the new AI lab has a diverse workforce. This is an opportunity to direct investment towards patients and communities where health inequalities remain stubbornly entrenched.

New technologies must be evaluated in real world settings to give patients, the public, and healthcare teams confidence that implementation is safe and will improve care. Yet, although the National Institute for Health and Care Excellence (NICE) has developed evidence standards frameworks for digital health technologies, ${ }^{5}$ consensus about evaluation methods is limited, and questions persist about whether evaluators will be able to gather the data that they need at the pace required. Questions also remain about how regulatory frameworks will evolve to deal with fast changing technologies, such as algorithms that are dynamically updated.

\section{Data scientists, technology incubators}

Many of the major innovations in data analytics from the past two decades have happened only with close NHS involvement. ${ }^{6}$ The AI lab will therefore need to support data science in the public sector as well as the private sector. The NHS has not invested sufficiently in its 10000 or so data analysts, ${ }^{7}$ but they are critical to solving healthcare problems and can also act as valuable bridges between clinicians, managers, and data scientists in industry.

We may also need to invest in more "technology incubators"-environments that bring together multidisciplinary teams (including patients) to develop AI solutions to healthcare problems. Developments such as DRIVE, a unit at Great Ormond Street Hospital to develop technologies for better care, have made a start, but more such units at greater scale will be needed to match the government's ambitious innovation agenda. ${ }^{8}$ $\mathrm{AI}$ is powered by data. Although the NHS potentially has the best health data in the world, local systems rarely communicate with each other, and the process of accessing and organising data for research is slow and costly. Harmonisation is a priority, but strategic questions remain-for example, how much health data should be stored in national databases and how much held locally and processed according to national standards.

\section{Fair value}

Another challenge lies in how health systems can obtain fair value when sharing data with private companies. NHS boards have been warned not to give data away too cheaply to private operators, ${ }^{9}$ but there is still too little transparency about how health data are being shared with the private sector, ${ }^{10}$ and 
ambiguity exists about how intellectual property should be managed. NHSX will host a new centre of expertise to tackle these questions and will need to make rapid progress.

Crucially, the public must be fully informed and proactively engaged in shaping decisions about how data are used and privacy protected. Commercial access to data remains a red line for some. ${ }^{11}$

\section{Supporting adoption}

Identifying a technological solution that works in one place is only half the battle; the bigger challenge is to get these solutions working well everywhere. Promising tools are being developed to help this process, ${ }^{12}$ but we need more investment in knowledge sharing infrastructure and better support for those adapting innovations for local use. ${ }^{13}$ Redesigning clinical workflows and patient pathways around technological innovation will take time and people, yet the NHS has a shortfall of 100000 staff. ${ }^{14}$ Unless these challenges are tackled through a clear national strategy, the potential of new technologies will not be fulfilled.

Competing interests: We have read and understood BMJ policy on declaration of interests and have no relevant interests to declare.

Provenance and peer review: Commissioned; not externally peer reviewed.

1 O'Dowd A. Government pins hopes on $£ 250 \mathrm{~m} \mathrm{Al} \mathrm{centre} \mathrm{for} \mathrm{faster} \mathrm{diagnosis} \mathrm{and} \mathrm{treatment.}$ BMJ 2019;366:I5106. 10.1136/bmj.15106 31399443

2 Department of Health and Social Care. Code of conduct for data-driven health and care technology. 2019. https://www.gov.uk/government/publications/code-of-conduct-for-datadriven-health-and-care-technology

3 Gould M. NHSX: giving patients and staff the technology they need. 24 Jun 2019. https: //healthtech.blog.gov.uk/2019/06/24/nhsx-giving-patients-and-staff-the-technology-theyneed/

4 Eubanks V. Automating inequality. St Martin's Press, 2018.
5 National Institute for Health and Care Excellence. Evidence standards for digital health technologies. 2019. https://www.nice.org.uk/Media/Default/About/what-we-do/ourprogrammes/evidence-standards-framework/digital-evidence-standards-framework.pd\#\# targetText=The\%20framework\%20directly\%20supports\%20relevant,and\%20 evidence\% 20levels\%20in\%20use.

6 Chenore T, Pereira Gray DJ, Forrer J, Wright C, Evans PH. Emergency hospital admissions for the elderly: insights from the Devon Predictive Model. J Public Health (Oxf) 2013:35:616-23. 10.1093/pubmed/fdt009 23440706

7 Bardsley M, Steventon A, Fothergill G. Untapped potential: investing in health and care data analytics. Health Foundation, 2019, https://www.health.org.uk/publications/reports/ untapped-potential-investing-in-health-and-care-data-analytics

8 Great Ormond Street Hospital for Children. New unit opening at Great Ormond Street Hospital set to revolutionise how technology is used in hospitals. Press release, 10 Oct 2018. https://www.gosh.nhs.uk/news/latest-press-releases/new-unit-opening-great-ormondstreet-hospital-set-revolutionise-how-technology-used-hospitals

9 Department of Health and Social Care. Creating the right framework to realise the benefits for patients and the NHS where data underpins innovation. 2019. https://www.gov.uk/ government/publications/creating-the-right-framework-to-realise-the-benefits-of-healthdata/creating-the-right-framework-to-realise-the-benefits-for-patients-and-the-nhs-wheredata-underpins-innovation

10 Naylor A, Magnusson J. Taking next steps to harness the value of health and care data. Future Care Capital, 2019. https://futurecarecapital.org.uk/policy/taking-next-steps-toharness-the-value-of-health-and-care-data/.

11 Wellcome Trust. The one-way mirror: public attitudes to commercial access to health data. 2015. https://wellcome.ac.uk/sites/default/files/public-attitudes-to-commercial-accessto-health-data-wellcome-mar16.pdf

12 Greenhalgh T, Wherton J, Papoutsi C, etal . Beyond adoption: a new framework for theorizing and evaluating non-adoption, abandonment, and challenges to the scale-up, spread, and sustainability of health and care technologies. $J$ Med Internet Res 2017;19:e367. 10.2196/jmir.8775 29092808

13 Horton T, llingworth J, Warburton W. The spread challenge. Health Foundation, 2018, https://www.health.org.uk/publications/the-spread-challenge.

14 Charlesworth A, Gershlick B, Firth Z, Kraindler J, Watt T. Investing in the NHS long-term plan. Health Foundation, 2019, https://www.health.org.uk/sites/default/files/upload/ publications/2019/S08_Investing\%20in\%20The\%20NHS\%20long\%20term\%20plan_ WEB_0.pdf

Published by the BMJ Publishing Group Limited. For permission to use (where not already granted under a licence) please go to http://group.bmj.com/group/rights-licensing/ permissionsThis is an Open Access article distributed in accordance with the Creative Commons Attribution Non Commercial (CC BY-NC 4.0) license, which permits others to distribute, remix, adapt, build upon this work non-commercially, and license their derivative works on different terms, provided the original work is properly cited and the use is non-commercial. See: http://creativecommons.org/licenses/by-nc/4.0/. 